\title{
LONG-TERM RESULTS OF TOTAL CONDYLAR KNEE ARTHROPLASTY IN RHEUMATOID ARTHRITIS
}

\author{
OLE KRISTENSEN, ADEL NAFEI, PER KJAERSGAARD-ANDERSEN, IVAN HVID， JøRN JENSEN
}

\author{
From the University Hospitals, Aarhus
}

\begin{abstract}
We have reviewed at an average period of ten years the results of 71 consecutive primary arthroplasties with the Insall-Burstein total condylar knee prosthesis in patients with rheumatoid arthritis. Their mean age at surgery was 52 years $(24$ to 72$)$.

At follow-up the overall results (Hospital for Special Surgery knee rating score) were excellent or good in $77 \%$, fair in $11 \%$ and poor in $11 \%$. There was residual pain in only $5 \%$ of patients with prostheses in situ; $58 \%$ could walk more than $500 \mathrm{~m}$, and the median range of motion was $108^{\circ}$. Eight knees had been revised. Five underwent arthrodesis because of deep infection and three needed revision arthroplasty for mechanical loosening. The crude survival rate of the arthroplasties was $89 \%$. The presence of radiolucency around the tibial component correlated significantly with the severity of residual pain.
\end{abstract}

In most cases, the indication for knee replacement is chronic joint pain not responding to conservative treatment. However, in patients with rheumatoid arthritis other factors must be taken in consideration, and these are also important when evaluating the outcome at follow-up. There are many reports of the long-term outcome of total knee replacement, but few of them deal separately with cases of rheumatoid arthritis.

We have evaluated the long-term results in patients with rheumatoid arthritis, primarily treated with the Insall-Burstein total condylar prosthesis.

\section{PATIENTS AND METHODS}

Between 1979 and 1982, we performed 139 consecutive primary total condylar knee arthroplasties on 95 patients with rheumatoid arthritis. The operative technique and the prosthesis used were those described by Insall, Tria and Scott (1979). The mean observation period was ten years (9 to 11). Thirty-five patients ( $49 \mathrm{knees)}$ died during the observation period, 14 (19 knees) were lost to followup, and the remaining 46 (71 knees) were reviewed.

O. Kristensen, MD, Registrar

A. Nafei, MD, Registrar

P. Kjaersgaard-Andersen, MD, Registrar

I. Hvid, MD, PhD, Chief Surgeon

J. Jensen, MD. Chief Surgeon

Department of Orthopaedic Surgery, Aarhus University Hospitals,

DK-8000 Aarhus C, Denmark.

Correspondence should be sent to $\mathrm{Dr} A$. Nafei at Herluf Trollesgade 7C, st, DK-8200 Åarhus N, Denmark.

(C) 1992 British Editorial Society of Bone and Joint Surgery

$0301-620 \mathrm{X} / 92 / 6466 \$ 2.00$

J Bone Joint Surg [ Br] 1992; 74-B : 803-6.
There were nine men ( 14 knees) and 37 women ( 57 knees) and their mean age was 52 years ( 24 to 72 ).

All patients were examined clinically and radiologically before operation. Rehabilitation began on admission, when they were instructed in active and passive muscle exercises, and in walking with crutches. Antibiotic and thrombosis prophylaxis was given to all patients. We used oral methicillin from the time of operation until the third postoperative day, and heparin 5000 IU subcutaneously twice daily from the day before operation until the patient was well mobilised, supervised active exercises and compressive stockings. The operating theatre was equipped with laminar air-flow. We aimed to achieve a tibiofemoral alignment between $3^{\circ}$ and $10^{\circ}$ of valgus, a neutral position of the prosthetic components (a tilt of less than $5^{\circ}$ ), a range of motion (ROM) greater than $95^{\circ}$ and a stable knee (a maximum of $5^{\circ}$ instability on full extension).

Lateral and anteroposterior radiographs were taken on the fifth postoperative day. Outpatient clinical and radiological examinations including a skyline view of the patella were performed 12 weeks postoperatively and at yearly intervals thereafter. Ahlbäck's (1968) classification was used pre-operatively to grade the severity of the joint destruction. The Hospital for Special Surgery (HSS) knee rating score (Insall et al 1976) was used, and the cementbone interfaces beneath the tibial component were evaluated according to the radiolucency score approved by the Knee Society (Ewald, Hsu and Walker 1989). The tibiofemoral alignment and the tilt of the tibial component were measured in all knees.

The patients' body-weight $(\mathrm{W})$ and height $(\mathrm{H})$ were measured at the time of surgery and a body-mass index 
(BMI) was recorded as $\mathrm{W} / \mathrm{H}^{2}$. Obesity was defined as a BMI > 28 (Quaade et al 1986).

Spearman's test was used for the correlation analysis and a $\mathrm{p}$ value of less than 0.05 was considered to be significant.

\section{RESULTS}

The HSS scores pre-operatively and at follow-up are shown in Table I. The poor group of eight consisted of five knees which had undergone arthrodesis because of deep infection, two in which revision arthroplasty had been performed for mechanical loosening and one with a recent femoral condylar fracture due to trauma. One knee in the fair group had clinical and radiological signs of loosening, and revision was planned. If the eight knees in which revision had been performed or was planned were considered as failures, the crude survival rate was $89 \%$.

The median total score for the knees with prostheses in situ was 84 points (22 to 98 ). Pre-operatively, it was 48 points (24 to 76). No significant correlation was found between the total score and the radiolucency score, the tibial tilt, the tibiofemoral alignment at follow-up, or the body-mass index at the time of surgery.

Table I. Distribution of 71 knees according to the Hospital for Special Surgery (HSS) knee rating score, pre-operatively and at follow-up. Figures in italic represent unchanged status

\begin{tabular}{lllll}
\hline & \multicolumn{4}{l}{ HSS score at follow-up } \\
\cline { 2 - 5 } $\begin{array}{l}\text { Pre-operative } \\
\text { HSS score }\end{array}$ & $\begin{array}{l}\text { Poor } \\
\mathbf{1 1 \%}\end{array}$ & $\begin{array}{c}\text { Fair } \\
11 \%\end{array}$ & $\begin{array}{l}\text { Good } \\
\mathbf{3 2 \%}\end{array}$ & $\begin{array}{l}\text { Excellent } \\
\mathbf{4 5 \%}\end{array}$ \\
\hline Poor $86 \%$ & 8 & 6 & 20 & 27 \\
Fair $13 \%$ & 0 & 1 & 3 & 5 \\
Good $1 \%$ & 0 & 1 & 0 & 0 \\
Excellent $0 \%$ & 0 & 0 & 0 & 0 \\
\hline
\end{tabular}

The numbers and percentages of knees in the different pain intensity categories pre-operatively and at follow-up are shown in Table II. At follow-up $94 \%$ of the patients with prostheses in situ had less knee pain than pre-operatively. A highly significant correlation was found between the severity of the residual pain and the radiolucency score $(r=0.33, p<0.01)$.

At follow-up $58 \%$ of the patients could walk more than $500 \mathrm{~m}$ compared with $8 \%$ pre-operatively, $15 \%$ could walk 100 to $500 \mathrm{~m}$ ( $33 \%$ pre-operatively) and $28 \%$ could walk less than $100 \mathrm{~m}(60 \%$ pre-operatively).

Table III shows the range of motion (ROM) preoperatively and at latest follow-up. This was over $95^{\circ}$ and functionally acceptable in $55 \%$ of knees at follow-up, but was between $60^{\circ}$ and $94^{\circ}$ in $44^{\circ} \%$. One knee had a ROM less than $60^{\circ}$. The median range at follow-up was $104^{\circ}$ to $111^{\circ}$ and the average gain was $16^{\circ}$.
At follow-up $85 \%$ of the knees with prostheses in situ were stable; $14 \%$ had instability of $6^{\circ}$ to $15^{\circ}$ and the knee with the recent femoral condylar fracture had instability of more than $15^{\circ}$.

The BMI showed no significant correlation with the intensity of the residual pain or with the radiolucency score.

Radiological analysis. Pre-operatively, according to Ahlbäck's (1968) scale, 16 knees were grade III, 29 were grade IV, and 19 were grade $V$ and the median tibiofemoral alignment was $6^{\circ}$ of valgus $\left(20^{\circ}\right.$ of valgus to $8^{\circ}$ of varus). Postoperatively, the median tibiofemoral alignment was $5^{\circ}$ of valgus (quartiles : $3^{\circ}$ and $6^{\circ}$ ). The median tilt of the tibial component was $3^{\circ}$ medially in the frontal view (quartiles : $1^{\circ}$ and $4^{\circ}$ ) and $1^{\circ}$ anteriorly on the side view (quartiles : $1^{\circ}$ posteriorly and $3^{\circ}$ anteriorly).

Significant radiolucent zones (over 4 points) were seen around three tibial components $(5 \%$ of the prostheses in situ). One of these knees was symptomatic with moderate pain.

No significant correlation was found between the radiolucency score and tibiofemoral alignment or the tilt of the tibial component. Nor did the combination of tibiofemoral malalignment and malpositioning of the

Table II. Distribution of 64 knees according to pain intensity, pre-operatively and at follow-up. Figures in italics represent unchanged pain status

\begin{tabular}{lllll}
\hline & \multicolumn{4}{l}{ Pain at follow-up } \\
\cline { 2 - 5 } Pre-operative pain & $\begin{array}{l}\text { Severe } \\
\mathbf{2 \%}\end{array}$ & $\begin{array}{l}\text { Moderate } \\
\mathbf{3} \%\end{array}$ & $\begin{array}{l}\text { Mild } \\
\mathbf{2 8 \%}\end{array}$ & $\begin{array}{l}\text { None } \\
\mathbf{6 7 \%}\end{array}$ \\
\hline Severe 58\% & 1 & 1 & 8 & 27 \\
Moderate 33\% & 0 & 0 & 7 & 14 \\
Mild 9\% & 0 & 1 & 3 & 2 \\
None 0\% & 0 & 0 & 0 & 0 \\
\hline
\end{tabular}

Table III. Distribution of 64 knees according to range of motion (ROM), pre-operatively and at follow-up. Figures in italics represent functionally acceptable range of motion

\begin{tabular}{lllll}
\hline & \multicolumn{5}{l}{ ROM at follow-up } \\
\cline { 2 - 5 } & $\begin{array}{l}<0^{\circ} \\
\mathbf{0} \%\end{array}$ & $\begin{array}{l}\mathbf{6 0} \text { to } 94^{\circ} \\
\mathbf{2 7} \%\end{array}$ & $\begin{array}{l}\mathbf{9 5 ^ { \circ }} \text { to } 104^{\circ} \\
\mathbf{2 7} \%\end{array}$ & $\begin{array}{l}>\mathbf{1 0 5} \\
\mathbf{4 5} \%\end{array}$ \\
\hline$<60^{\circ} 3 \%$ & 0 & 7 & 4 & 1 \\
$60^{\circ}$ to $94^{\circ} 31 \%$ & 0 & 12 & 11 & 4 \\
$95^{\circ}$ to $104^{\circ} 30 \%$ & 1 & 6 & 1 & 4 \\
$>105^{\circ} 37^{\circ} \%$ & 0 & 3 & 5 & 5 \\
\hline
\end{tabular}

tibial component influence the occurrence of significant radiolucent zones (Fisher's exact test: $p=0.74$ ).

Complications. There were eight serious complications ( $11 \%$ ), but no deaths. One patient had patellar osteonecrosis, probably from the use of both medial and lateral 
parapatellar incisions. Patellectomy was performed and this knee was rated fair at follow-up. One comminuted femoral condylar fracture occurred after trauma necessitating revision arthroplasty, and one supracondylar femoral fracture occurred in a patient in whom there was a deep notch $(7 \mathrm{~mm})$ in the anterior femoral cortex. The fracture was treated by osteosynthesis, and the knee was rated good at follow-up. There were five cases of deep infection; detailed in Table IV. Regression analysis showed a linear correlation between the occurrence of deep infection and the time elapsed after surgery (slope $=$ 0.047 , correlation coefficient $=0.987, \mathrm{p}=0.0018$ ) prosthesis. This finding is in agreement with that reported by Scuderi et al (1989).

Our series of patients can be directly compared with the simultaneous series of knee replacements performed in our department for osteoarthritis (Nafei et al 1992). Using revision or recommended revision as the definition of failure, the osteoarthritic group had a significantly better ten-year crude survival of the prosthesis than the rheumatoid group (two failures out of 93 versus nine failures out of 71 ; Fisher's exact test: $p=0.009$ ).

The overall results were similar as to the median total score and there was no significant difference in score

Table IV. Details of five arthrodeses performed for deep infections after knee arthroplasty

\begin{tabular}{llllllll}
\hline Case & Age/Sex & Steroid & $\begin{array}{l}\text { Interval between } \\
\text { surgery and } \\
\text { infection (mth) }\end{array}$ & Micro-organism & Route of infection & Other foci/disease & $\begin{array}{l}\text { Healing time of the } \\
\text { arthrodesis (mth) }\end{array}$ \\
\hline 4 & $64 / \mathrm{F}$ & No & 5 & Enterobacter cloacae & $\begin{array}{l}\text { Postoperative skin } \\
\text { necrosis }\end{array}$ & Arteriosclerosis & 3 \\
5 & $54 / \mathrm{F}$ & Yes & 59 & $*$ & $\begin{array}{l}\text { Haematogenous } \\
\text { Crural abscess } \\
\text { Chronic nephropathy }\end{array}$ & Nonunion \\
6 & $72 / \mathrm{F}$ & No & 90 & $\begin{array}{l}\text { Streptococcus haemolyticus } \\
\text { group } A\end{array}$ & Haematogenous & & 5 \\
7 & $40 / \mathrm{F}$ & No & 36 & $\begin{array}{l}\text { Staphylococcus aureus } \\
\text { Proteus morganii }\end{array}$ & $\begin{array}{l}\text { Haematogenous } \\
\text { Haematogenous }\end{array}$ & Cubital abscess & 6 \\
$8 \dagger$ & $40 / \mathrm{F}$ & No & 72 & Sacral bedsore & 6 \\
\hline
\end{tabular}

"clinical signs of infection, but negative culture results

the same patient as case 7 . Arthrodeses were performed bilaterally 3.5 and 6 years after the primary operations

Aseptic loosening. Three patients had aseptic loosening. One 26-year-old woman who had had revision arthroplasty eight years after the primary procedure had a total score of 85 points two years after the revision. A 67-yearold woman had revision arthroplasty at nine years and one year later the knee was rated good. A 50-year-old man with bilateral replacements had progressive symptomatic loosening on one side at six years but revision arthroplasty was postponed because of the patient's cardiopulmonary status.

\section{DISCUSSION}

The indications for knee replacement in patients with rheumatoid arthritis differ substantially from those in other diagnostic groups. The disease is often progressive with involvement of many joints and also the upper extremities which limits the use of walking aids. Evaluation of the results of treatment should therefore be focused on the whole patient rather than on the surgical outcome in the knee alone. Unfortunately, the HSS knee rating score, used from the beginning of this study more than ten years ago, does not appropriately reflect this approach.

In a survivorship analysis of many different types of knee prostheses, Rand and Ilstrup (1991) found that patients with rheumatoid arthritis had a lower risk of failure than other diagnostic groups. This was not the case, however, in patients treated with the total condylar gain between the two groups. The distribution of the knees among the total score subgroups at follow-up also showed no significant difference (chi-squared test).

Only in two categories of results was there a noticeable difference. Pre-operatively, the walking ability of both groups of patients was equally poor and both showed a marked improvement ten years after surgery. At latest follow-up, however, the rating of the rheumatoid patients was significantly lower than that of the osteoarthritic group (chi-squared test: $p<0.02$ ). We do not consider this as a difference in surgical success, but rather a reflection of the limitations of treating a systemic disease by local surgical intervention. The ROM was also significantly less in the rheumatoid group both preoperatively and at follow-up compared with the osteoarthritic group. The borderline of a functionally acceptable ROM was defined as $95^{\circ}$, but we considered whether the minimum acceptable postoperative ROM should have been increased to $105^{\circ}$ in rheumatoid arthritis as recommended by Sledge and Walker (1984), thus giving the patient the possibility of rising from a chair with very little load on the upper extremities. If this criterion were applied to the present series only one-fifth of the knees would satisfy it.

The rate of deep infection reported after knee arthroplasty varies from $1 \%$ to $11 \%$ (Jones et al 1979 ; Grogan et al 1986; Laskin 1990; Nafei, Steinke and Horlyck 1990). In these reports and in our series the rate of deep infection in the rheumatoid patients was slightly 
higher than in the osteoarthritic patients, although we could not show statistical significance (Nafei et al 1992). The deep infections in the rheumatoid group were almost uniformly distributed over the observation period.

Conclusion. Nine to 11 years after knee arthroplasty with the total condylar implant there was a high rate of pain relief and improved walking ability with a prosthesis crude survival rate of $89 \%$.

No benefits in any form have been received or will be received from a commercial party related directly or indirectly to the subject of this article.

\section{REFERENCES}

Ahlbäck S. Osteoarthrosis of the knee: a radiographic investigation. Acta Radiol 1968; Suppl 277:7-72.

Ewald FC, Hsu HP, Walker PS. Is kinematic total knee replacement better than total hip replacement? Orthop Clin North Am 1989; 20:79-88.

Grogan TJ, Dorey F, Rollings J, Amstutz HC. Deep sepsis following total knee arthroplasty: 10 year experience at the University of California at Los Angeles Medical Center. J Bone Joint Surg [Am] $1986 ; 68-A: 226-34$
Insall JN, Ranawat CS, Aglietti P, Shine J. A comparison of four models of total knee-replacement prostheses. J Bone Joint Surg [ Am] 1976; 58-A :754-65.

Insall J, Tria AJ, Scott WN. The total condylar knee prosthesis: the first 5 years. Clin Orthop 1979; 145:68-77.

Jones EC, Insall JN, Inglis AE, Ranawat CS. GUEPAR knee arthroplasty results and late complications. Clin Orthop 1979; 140:145-52.

Laskin RS. Total condylar knee replacement in patients who have rheumatoid arthritis: a ten-year follow-up study. J Bone Joint Surg [Am] 1990; 72-A :529-35.

Nafei A, Steinke MS, Horlyck E. Total condylar knee arthroplasty in the treatment of osteoarthritis and rheumatoid arthritis: a comparative study at 4-8 years follow-up. Am J Knee Surg 1990; 3:59-64.

Nafei A, Kristensen O, Hvid I, Kjaersgaard-Andersen P, Jensen J. Longterm results of the cemented total condylar knee arthroplasty: a 9-11 year follow-up. Acta Orthop Scand 1992; 63 (Suppl 248):51-2.

Quaade F, Andersen T, Astrup A. Adipositas. In: Thaysen JH, Christensen LK, Lorenzen I, eds. Medicinsk kompendium. Copenhagen: NYT Nordisk Forlag Arnold Busck, 1986:2100-14.

Rand JA, Ilstrup DM. Survivorship analysis of total knee arthroplasty: cumulative rates of survival of 9200 total knee arthroplasties. J Bone Joint Surg [Am] 1991; 73-A :397-409.

Scuderi GR, Insall JN, Windsor RE, Moran MC. Survivorship of cemented knee replacements. J Bone Joint Surg [Br] 1989; 71. B :798-803.

Sledge CB, Walker PS. Total knee arthroplasty in rheumatoid arthritis. Clin Orthop 1984; 182:127-36. 